\title{
Research on the Construction of Jingdezhen Ceramic Creative Culture Industry System from the Perspective of Ecological Economy
}

\author{
Weiping Yuan
}

Polytechnic institute of Jiangxi Science and Technology Normal University, Jiangxi, Nanchang, 330000

Keywords: Ecological economy; Jingdezhen ceramics; creative culture industry

\begin{abstract}
Ceramic cultural resources are the most representative resources of Jingdezhen, and the ceramic creative culture industry is one of the most promising industries in Jingdezhen's economic development. Promoting the development strategy of "Cultural Porcelain Capital” and promoting the development of ceramic creative culture industry is an inevitable development requirement in the era of ecological economy. To construct the Jingdezhen ceramic creative culture industry system from the perspective of ecological economy, it is necessary to conscientiously implement the concept of sustainable development and conscientiously implement various development safeguard measures. Based on the analysis of the principles of Jingdezhen ceramic creative culture industry system construction under the perspective of ecological economy, this paper studies its construction content and aims to promote the sustainable development of Jingdezhen ceramic creative culture industry.
\end{abstract}

\section{Introduction}

With the continuous development of the social economy, all walks of life have also developed rapidly, and the cultural industry is no exception. Jingdezhen ceramic culture industry is not only one of the important cultural resources of Jiangxi, but also a great treasure in the Chinese national civilization. Jingdezhen ceramic creative culture industry, as the most potential industry in Jingdezhen ceramic culture industry, plays an irreplaceable role in promoting local economic development. However, the concept of sustainable development is being promoted at home and abroad. Therefore, the construction of Jingdezhen ceramic creative culture industry system should also strictly follow the principle of ecological economic development to ensure the coordinated development of ecology and economy.

\section{Principles for the Construction of Jingdezhen Ceramic Creative Culture Industry System from the Perspective of Ecological Economy}

In order to meet the requirements of ecological and economic development, in the process of constructing Jingdezhen ceramic creative culture industry system, the following principles should be strictly followed: First, adhering to the principle of integration of ceramic creative culture industry and Jingdezhen humanistic environment. The history and culture of Jingdezhen ceramics is profound, providing a good social environment for the gathering of ceramic creative culture industry. In the process of establishing a ceramic creative culture industry cluster and shaping individual brands, the humanistic environment of Jingdezhen should be fully considered. In addition, during the research and development of products, we should also do a good job in protecting the local human environment, and actively protect the water and land terminal, the Old City City Pool Office, the Porcelain Line Chaixing Baitu Line, the Gaoling Ancient Mine, the Blank House Kiln House, the Old Street Lane, etc. Material heritage, constantly optimize and improve the industrial connotation to meet the needs of ecological economic development [1]. Second, it is necessary to ensure that the ceramic creative culture industry development strategy meets the requirements of comprehensive economic and social development. The development strategy of Jingdezhen ceramic creative culture industry should not only follow the development requirements of the national cultural industry, but also must follow the Jiangxi Province industrial development strategy, meet 
the ecological economic development planning strategy requirements, make full use of various resources, and strive to obtain at the lowest cost. The greatest development results. Third, we should actively cultivate leading enterprises while giving play to the advantages of the group. We should pay attention to the cultivation of leading enterprises, take the leading enterprises as the fulcrum, give full play to the group advantages of other enterprises, strengthen cooperation and scientific division of labor, and strive to build an advantageous industrial chain and industrial cluster with international competitiveness [2]. The fourth is to adhere to the principle of integration of corporate entities and government guidance. Enterprises should continuously improve their market competitiveness according to the needs of market development, gradually establish industrial agglomeration groups in the development process, and rationally plan the gathering areas and industrial parks to promote their own better development. The government should strive to provide some preferential policies for the development of Jingdezhen ceramic creative culture industry, continuously optimize the public service system, and create a good environment for the development of ceramic creative culture industry.

\section{The construction of Jingdezhen ceramic creative culture industry system from the perspective of ecological economy}

\subsection{Ceramic Culture Tourism}

The market value and cultural heritage of the intangible cultural heritage and material cultural heritage of Jingdezhen should be further developed, and the exchanges and cooperation between scientific research institutions, tourism bureaus and tourism enterprises should be strengthened, and various advanced publicity technologies and high-tech technologies should be fully utilized to strengthen Design and development of ceramic tourism products. Some international popular elements can be integrated into typical creative cultural products such as "porcelain dance", "porcelain music" and "ceramic culture wall", and strive to enhance the market competitiveness of ceramic culture tourism projects. At the same time, it must be combined with the local ecological environment. It highlights cultural themes such as "Red Revolution" and "Millennium Porcelain Capital" [3]. In addition, we should make full use of local tourism resources, develop creative projects such as rural leisure vacations or hand-made porcelain experience tours, guide the industry to focus on and promote the sustainable development of Jingdezhen cultural tourism industry.

\subsection{Ceramic advertising}

In recent years, the advertising industry in Jingdezhen has achieved good development results and has entered a period of stable development. The focus of the current work is how to fully integrate various advertising resources, strengthen supervision, and avoid false advertising. In addition to the local ceramics professional publications to increase the promotion of Jingdezhen ceramics creative culture industry, such as "China Ceramic Industry", "Jingdezhen Ceramics", "Ceramic Journal", etc., should also be in "Taocheng Daily" and "Ceramic Information News" "Specialized ceramic newspapers published a special edition of Jingdezhen column, established an influential professional ceramic media organization, and strengthened the promotion and promotion of Jingdezhen ceramic creative culture industry [4].

\subsection{Ceramic Exhibition}

Jingdezhen should strengthen the construction of a multi-level cultural festival exhibition system, focusing on holding some internationally influential festivals, such as China Jingdezhen International Ceramics Expo, to expand the attraction of Jingdezhen creative culture industry. At the same time, support should be given to the festivals of the Fuliang Tea Culture Festival, the Yaoli Tourism Festival, the Jingdezhen Traditional Ceramics Crafts Porcelain Exhibition and other local propaganda ceramic culture features to form a multi-festival convention and exhibition economic system. It is necessary to focus on the construction of exhibition facilities around Jingdezhen City, and strive to build Jingdezhen into a creative culture exhibition city. 


\subsection{Ceramic network culture}

The network culture industry is also known as the "digital entertainment industry" and "digital content industry", which emphasizes "content industry", which is mainly an industry that uses information resources to carry out research and development, trading, creativity, distribution, and production of products or services. Ceramic network culture mainly includes the following two types: First, digital and networked traditional cultural industries, the most typical of which is "China Science Expo - Ceramics Museum". The second is based on the information network, and the content and form are different from the traditional ceramics of new ceramic creative culture products. "Image Jingdezhen Xue" is one of the most representative new ceramic creative culture products. We should make full use of market forces and actively strive for financial support from domestic and foreign large enterprises. At the same time, we should pay attention to the construction of network infrastructure, strengthen the construction and supervision of networks such as "China Porcelain Network" and "China Jingdezhen", and give full play to the promotion of those networks. Role to promote the better development of the ceramic network culture industry.

\section{Jingdezhen ceramic creative culture industry system construction attention points}

\subsection{Strengthening the construction of public service platforms}

Jingdezhen City has established the country's only ceramic quality testing center, building ceramics engineering center and information center approved by the state, and the world's major porcelain producing city mayor summit and Wuqu Ceramic International Expo have been successfully held in Jingdezhen. In addition, Jingdezhen's scientific research level in ceramics has also been significantly improved. It is suggested that these resources can be fully utilized to strengthen the construction of Jingdezhen ceramic creative industry public service platform, and to build a technical service and information exchange platform for the development of Jingdezhen ceramic creative culture industry.

\subsection{Strengthening the construction of intellectual property protection system}

Intellectual property is the core asset of the creative industry, and the value of creative achievements is mainly reflected through the transaction and development of intellectual property rights. Therefore, during the construction of Jingdezhen ceramic creative culture industry system, we should do a good job in the construction of intellectual property protection system, so as to stimulate the creativity and highlight the value of ceramic creative achievements. Ceramic creative individual, government, ceramic creative enterprise and industry association are the main bodies of Jingdezhen ceramic creative industry. They play an important role in protecting the intellectual property of ceramic creative industry and realizing the industrialization of ceramic creative products. Therefore, it is recommended that individuals, governments, enterprises and industry associations should actively participate in the construction of creative intellectual property protection systems. Individuals of creatives should give full play to their advocacy functions; the government should implement the preparation of creative intellectual property protection systems; Play a protective function; industry associations should play a guiding and communication role.

\section{Conclusion}

To sum up, to construct the Jingdezhen ceramic creative culture industry system from the perspective of ecological economy, we must adhere to the principle of integration of ceramic creative culture industry and Jingdezhen human environment, and ensure that the ceramic creative culture industry development strategy closely follows the requirements of comprehensive economic and social development. Give full play to group advantages, actively cultivate leading enterprises, and strive to build and develop creative culture industries such as ceramic culture tourism, ceramic advertisements, ceramic exhibitions and ceramic network culture, in order to promote the harmonious development of Jingdezhen ceramic creative culture industry and ecology, and ensure 
social economy. Sustainable development.

\section{References}

[1] Wu Wenbiao, Rao Yu, Wang Wensheng. On the Construction of Regional Cultural Industry Brand_-Taking Jingdezhen Ceramic Culture Creative Industry as an Example[J]. Journal of Ceramics, 2016(04): 430-434.

[2] Yu Bin, Yang Chao, Xiao Wei. Research on Cultural Ecology and Industrial Construction of Jingdezhen from the Perspective of Landscape Ecology[J]. Commercial and Economic Research,2016(02):208-209.

[3] $\mathrm{Hu}$ Linrong, Liu Bingfeng. Evaluation of the Ecosystem of Ceramic Culture and Creative Industry__ Taking Jingdezhen as an Example[J]. Corporate Economy, 2015(06): 136-139.

[4] Xiong Wei. Research on the Improvement Strategy of Jingdezhen Ceramic Creative Culture Industry System[J]. Times Finance, 2014(33): 271+281. 